\title{
How theory can go wrong: the case of simplicity and likelihood in perception
}

\author{
Michael Kubovy \\ University of Virginia
}

\begin{abstract}
This article consists of two parts. The first is a reconstruction of the opposition between explanatory principles in perception: simplicity and likelihood. The second offers a resolution of this long-standing debate.

1. The debate. After Mach presented his balanced and prescient views about likelihood and simplicity, a schism occurred between two camps: the Helmholtzian/Inferential camp — which emphasized the role of likelihood and discounted the role of simplicity — and the Gestaltist/Goodness camp which emphasized the role of simplicity and discounted the role of likelihood. An analysis of the debate leads us to conclude that the opposition between the two is illusory and that the debate is fruitless.

2. Resolving the debate by reformulating the question. We propose to treat perceptual systems as model-building devices that can produce models of varying degrees of complexity. Such models can be assessed in two ways: (a) the goodness of their fit to the information being modeled (the minimization of "bias"), which is greatest when the model is complex, and (b) their stability from situation to situation (the minimization of "variance"), which is greatest when the model is simple. After showing how model-building devices can balance these opposing criteria, we summarize evidence that perceptual systems do not minimize bias and an experiment that might serve as a model for empirical research on this question.

Keywords: AIC, Bayes's Theorem, bias-variance tradeoff, Brunswick, Gestalt, Helmholtz, interface theory of perception, Mach, minimal description length, model-selection criteria, Perceptual Interface Theory, Prägnanz, Structural Information Theory
\end{abstract}

Corresponding author: kubovy@virginia.edu. 


\section{Contents}

$\begin{array}{ll}\text { Introduction } & 3\end{array}$

$\begin{array}{ll}\text { An unproductive opposition } & 4\end{array}$

The Inferential camp . . . . . . . . . . . . . . . . . . . . 4

Focus on the prior ....................... 6

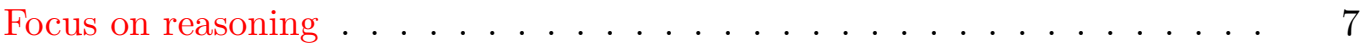

The Goodness camp . . . . . . . . . . . . . . . . . . 7

Simplicity vs. likelihood was the wrong question . . . . . . . . . . . . 10

Part 2: The way forward - The question of optimal complexity 12

Evolution and perceptual models . . . . . . . . . . . . . . . . 12

The optimal complexity of models . . . . . . . . . . . . . . . . . . 14

A case study: the map of the London Underground . . . . . . . . . . . . . . 14

The bias-variance tradeoff . . . . . . . . . . . . . . . . 16

Perceptual mechanisms and the best buy . . . . . . . . . . . 18

$\begin{array}{lr}\text { References } & 20\end{array}$ 
The purpose of this paper is to raise concerns about the way psychologists formulate theories. To do so we will use the example of an important debate in the field of perceptual organization: is perceptual organization better understood as the product of a simplicity principle or of a likelihood principle?

Two theoretical ideas are often invoked in discussions of perceptual organization, where they are called principles: simplicity and likelihood (Pomerantz \& Kubovy, 1981). In the first part of this article, after reviewing the history of this opposition, we will see why pitting these principles against each other is unproductive. The second part recasts this opposition, and proposes that we think of perceptual systems as model-construction devices that must balance (a) the goodness of their fit to reality - which is greatest when they are complex, against (b) their stability — which is greatest when they are simple.

We begin with Mach (1897) because he is one the rare scholars who mentions both principles, which he calls the principles of economy and probability. Here is how he defines them (pp. 94-5):

Principle of Probability: "the visual sense acts in conformity with the habits which it has acquired through adaptation to the life-conditions of the species and the individual."

Principle of Economy: "the visual sense never of itself puts forth greater efforts than are demanded by the excitation."

And then he illustrates by asking how we might account for a simple observation:

When we look at a straight line in a ... drawing, we always see it as a straight line in space, although [it] may correspond to an unlimited number of different plane spatial curves. $(\text { p. } 95)^{1}$

He notices that either principle will do. According to the principle of probability,

... only in ... special case[s] ... will it [a plane spatial curve] be delineated ... as a straight line. It is thus extremely improbable that a plane curve should ever appear a straight line, while ... [the projection of a] straight line in space is always [a straight line on] both retinas ... . The most probable object, therefore, answering to a perspective straight line, is a spatial straight line. (p. 95)

And according to the principle of economy,

... every point of a straight line in space marks the mean of the depth-sensations of the neighboring points. Thus the straight line in space represents a minimum of departure from the mean of the depth-sensations; and the assumption forthwith presents itself that the straight line is seen with the least effort. [Every] deviation of a sensation from the mean of the adjacent sensations ... exacts a special effort on the part of the sense-organ. Every new turn of a curve, every projection or

\footnotetext{
${ }^{1}$ It took a century for this phenomenon to be recognized by Lowe and Binford — 1985 , pp. 320-321—who dubbed it the collinearity phenomenon.
} 
depression of a surface, involves a deviation of some space sensation from the mean of the surrounding field ... . (pp. 96-7, emphasis mine $)^{2}$

Having shown that both principles are applicable to the collinearity phenomenon, he concludes that:

The visual sense acts therefore in conformity with the principle of economy, and, at the same time, in conformity with the principle of probability, when it exhibits a preference for straight lines. (p. 96)

A few pages later, he forestalls the overgeneralization of this theoretical ambiguity to all perceptual phenomena by noting that in drawings "all angles exhibit the tendency to ... [be interpreted as the projection of] right angles," 3 with respect to which the "principle of economy offers me no enlightenment" (p. 104).

\section{An unproductive opposition}

As mentioned earlier, Mach is an exception among thinkers. The others focus on just one principle. As a result they fall into two opposing camps (Figure 1). The Inferential camp (the left-hand, salmon-colored branch) consists of followers of Helmholtz. They are interested in the likelihood principle, which is much the same as saying that perception requires inference, or that it is ratiomorphic (Brunswik, 1955, p. 207) or even, as we will see later, is an instance of Bayesian inference. In contrast, the members of the Goodness camp (the right-hand branch, in steel blue) are followers of the Gestalt school, who are interested in the simplicity principle, in "goodness," or in "Prägnanz" (Koffka, 1935/1963, p. 110).

\section{The Inferential camp}

The touchstone of this camp is Helmholtz's $(2000, \S 26)$ description of unconscious inference:

such objects are always imagined as being present in the field of vision as would have to be there in order to produce the same impression on the nervous mechanism, the eyes being used under ordinary normal conditions. ... (p. 2)

Although the likelihood principle is not mentioned, it comes into play in the phrase "under ordinary normal conditions," by implying that under some extraordinary (or abnormal) conditions, the same impression may be produced by a different object. Otherwise put, unconscious inferences are solutions to inverse problems (Pizlo, 2001), defined as follows:

Using a physical theory for predicting the results of observations corresponds to solving the 'forward modelling problem.' The reciprocal situation, using the result of measurements to infer the values of the parameters representing a system, corresponds to the 'inverse modelling problem.'

\footnotetext{
${ }^{2}$ Here too Mach is decades ahead of his time. He anticipates a key observation by Attneave (1954), subsequently formalized by Feldman and Singh (2005): along a contour, information is concentrated where its direction changes most.

${ }^{3}$ This is true, subject to the constraints of Perkins's laws (Kubovy, 1986; Perkins, 1968, 1971, 1972).
} 


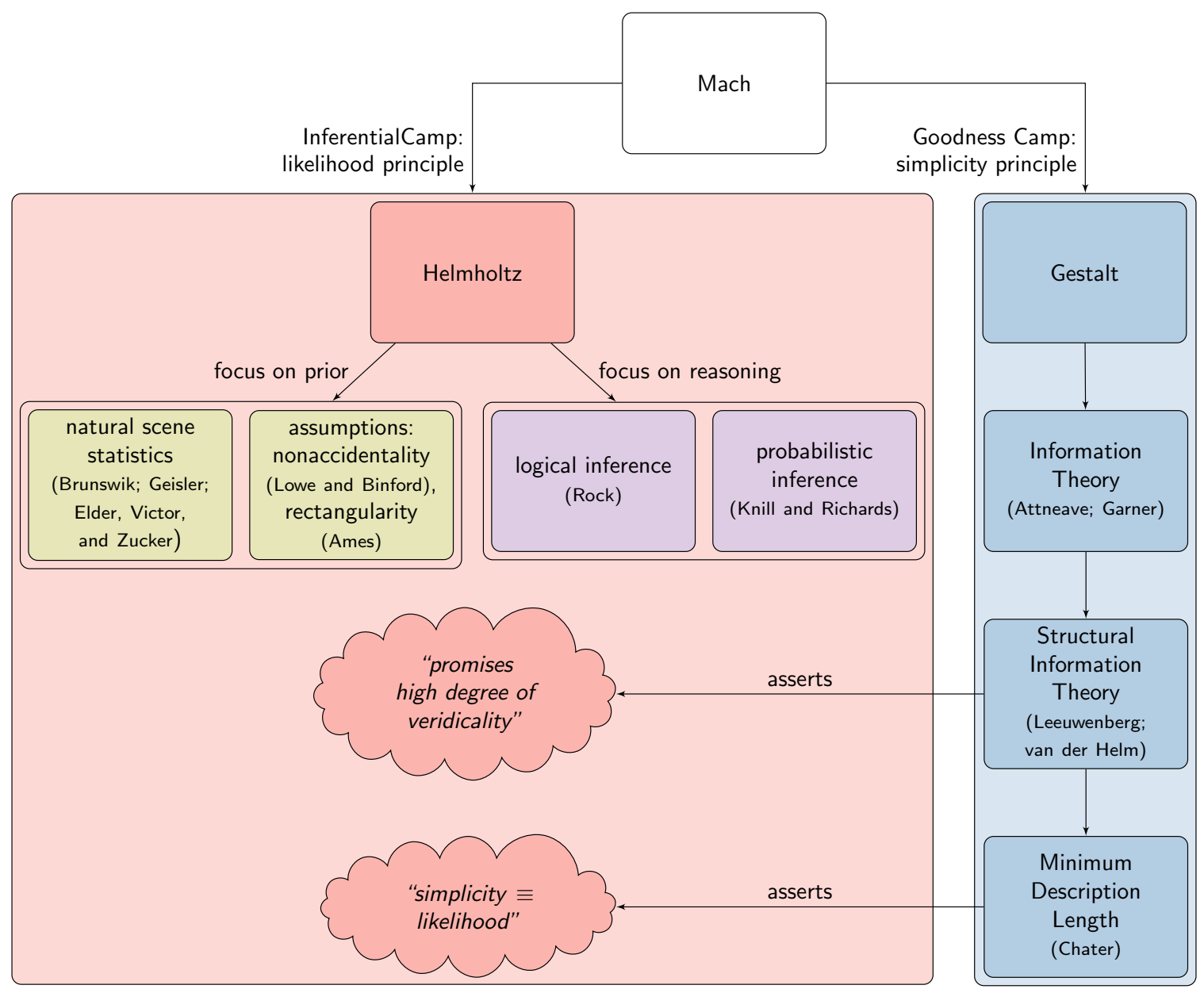

Figure 1. Conceptual map of the opposition. The focus on prior and the focus on reasoning are discussed on pages 6 and 7 respectively. Their background colors correspond to those in Figure 2.

Whereas the forward problem has (in non-quantum physics) a unique solution, because of the causality principle, the inverse problem may have many solutions - when different models of the system predict similar observations, or no solution at all (inconsistent data).(Tarantola, 2006, p. 492)

In philosophy of science this form of reasoning has been called inference to the best explanation (Harman, 1965). Neuroscientists (Jaynes, 1988) and psychologists (Knill, Kersten, \& Yuille, 1996, p. 15) have equated it with Bayesian models of inference (which we represent schematically in Figure 2), a position to which — after some hesitation (Salmon, 2001) philosophers have been coming around (Cabrera, 2017; Henderson, 2014).

Bayesian inference requires (a) prior information about the prevalence and cooccurrence of features in the visual world, which it uses to (b) infer features of the visual world by combining this prior information with its sensory state (what Helmholtz calls the "impression on the nervous mechanism") and information about the likelihood. 


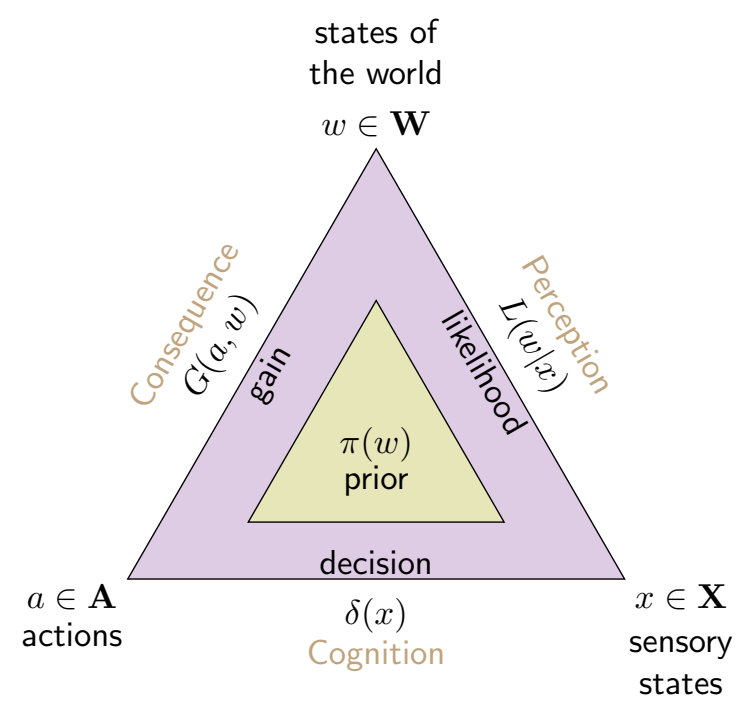

Figure 2. The Bayesian model of perceptual inference (after Maloney \& Mamassian, 2009, Figure 1). The colors of the prior component (willow-green) and the inferential component (violet) correspond to the focus on prior and the focus on reasoning in Figure 1.

Although some psychophysicists were impressed by how well human observers approximated the optimality of ideal observers (Tanner \& Norman, 1954), Helmholtzians need not be proponents of optimality. One can think of perception as inference without requiring that it possess perfect information or even follow the mathematical form of Bayes's theorem (Bowers \& Davis, 2012; Jones \& Love, 2011; Maloney \& Mamassian, 2009; Purves, Monson, Sundararajan, \& Wojtach, 2014).

Indeed, Helmholtzians have not focused on the precise application of Bayes's theorem. Instead, they split into two groups: (a) those who focus on the prior and search for evidence for the use of prior information (willow-green-colored triangle); (b) those who focus on reasoning and seek evidence for the inferential process itself (violet-colored triangle).

Focus on the prior. Researchers who focus on the prior, study ways in which perceptual systems use information that is not available in the current stimulus. They go about this in three ways.

Some have sought evidence that perceptual systems rely on non-testable assumptions about the input, typically called a priori constraints. An example of one such constraint has come to be know as the principle of nonaccidental image regularity (Kanade, 1983; Lowe \& Binford, 1985):

regular properties observable in the picture do not occur by accident, but are projections of some preferred corresponding 3D properties. (Kanade, 1983, p. $792)$

Or, more simply: assume that objects do not happen to be in a special position or orientation vis-à-vis the eye.

Others have chosen to assume that the visual system has internalized (perhaps over evolutionary time) probable features of objects. An example is the assumption of 
rectangularity, with which Ames (1951) explained the paradoxical appearance and motion of his rotating trapezoidal window. ${ }^{4}$

The third approach has been to show how perceptual systems rely on ecological information (also perhaps acquired over evolutionary time). As Geisler (2007) says:

Analyzing natural scene statistics within the Bayesian framework allows one to determine how a rational visual system should exploit those sources of information.

(p. 169)

Research on scene statistics starts with Brunswik and his colleagues (Brunswik, 1940, 1944; Brunswik \& Kamiya, 1953; Tolman \& Brunswik, 1935). To illustrate, in a study of the judgment of sizes of objects seen from different distances, he reports a high correlation between the perception of object size (the perceptual response in Figure 3) and the actual

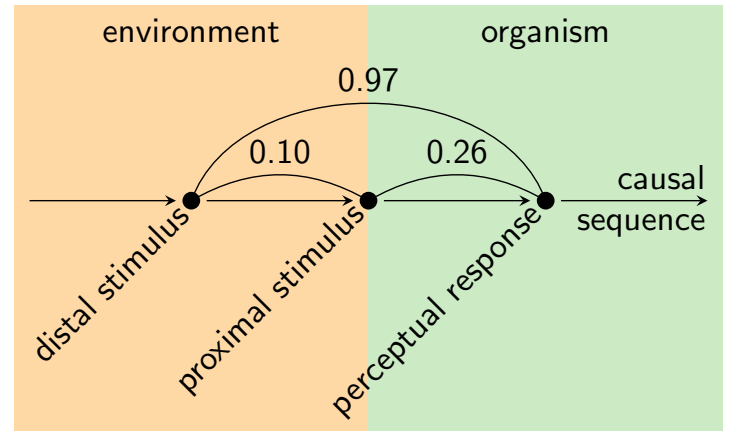

Figure 3. Dependencies (here characterized by correlation coefficients) among distal stimuli, proximal stimuli, and perceptual responses (based on Brunswik, 1940, Table 2).

size of objects (the distal stimulus), despite the low correlation between these and the angle they subtend at the eye (the proximal stimulus). ${ }^{5}$

Focus on reasoning. Researchers who focus on reasoning wish to produce evidence that "perception is rational" (Rock \& Gilchrist, 1975, p. 581). Over the last three decades of the 20th Century, this approach was exemplified by three influential books, The Intelligent Eye (Gregory, 1970), The Logic of Perception, (Rock, 1983) and Visual Intelligence (Hoffman, 1998). Even though they make no mention of ideal observers, optimality, or Bayes's theorem, ${ }^{6}$ the idea of Perception as Bayesian inference (Knill \& Richards, 1996) is deeply rooted in their work. ${ }^{7}$

\section{The Goodness camp}

The Gestalt psychologists sidestep the question of the relation between simplicity and likelihood by endorsing the simplicity principle, and deprecating likelihood. They reject the

\footnotetext{
${ }^{4}$ Shepard $(1984,1994,2001)$, is the most persuasive exponent of the idea of internalization. For a skeptical analysis, see Kubovy and Epstein (2001).

${ }^{5}$ To this day, this remains a vigorous field of research (Elder, Victor, \& Zucker, 2016; Feldman, 2013; Jones \& Love, 2011; Kubovy, Epstein, \& Gepshtein, 2013).

${ }^{6}$ Actually, Hoffman does mention Bayes on pp. 10 and 206, but it's not in the index.

${ }^{7}$ This too continues to be a lively research program (Aggelopoulos, 2015; Feldman, 2016a; Maloney \& Mamassian, 2009; Vincent, 2015).
} 
likelihood principle because they are (a) determined to avoid even a hint of associationism (Koffka, 1922, pp. 534-5); (b) inclined to believe that Gestalt phenomena are a reflection of inherent (or autochtonous) properties of brain processes. Their version of the simplicity principle (surveyed by Hatfield \& Epstein, 1985) consists of two distressingly vague notions:

Prägnanz: This concept can be rendered in English (depending on context) as brevity, concision, incisiveness, pithiness, poignance, precision, simplicity, or succinctness.

Goodness: Percepts "will always be as 'good' as the prevailing conditions allow" (Koffka, 1935/1963, p. 110).

These ideas go hand-in-hand with the belief that Prägnanz and goodness are not merely properties of perception - they occur in physical processes as well (Koffka, 1915; Köhler, 1920; Wertheimer, 1912). For instance, when electrostatic processes in the brain settle into a state of equilibrium, they minimize the system's potential energy, insuring that the corresponding percept will be 'good.' The Gestalt psychologists thought that this parallel between perception and neural processes is a manifestation of a general isomorphism between perception and brain processes, a claim that released a decades-long flood of exegetic ink (Luchins \& Luchins, 1999).

The introduction of information theory (Shannon, 1948) into psychology (Aborn \& Rubenstein, 1952; Attneave, 1954, 1955; Fitts, 1954; Grossman, 1953; Hick, 1952; Miller, 1953) was a godsend to those who were irritated by the nebulous nomenclature of the Gestalt psychologists. $^{8}$ And so they set about to apply Shannon's theory to the quantification of "goodness" (Attneave, 1954, p. 186). Although this approach produced some valuable ideas ${ }^{9}$ it says nothing about the resolution of inverse problems, i.e., about conflicting interpretations of visual input.

This is why Leeuwenberg and his colleagues developed Structural Information Theory (SIT: Leeuwenberg, 1967; Leeuwenberg \& van der Helm, 2013). Consider the pattern in the center of Figure 4, which is surrounded by diagrams representing four plausible ways to interpret it. Each of these can be given a descriptive code, a recipe for the reconstruction of the pattern. According to SIT, the interpretation whose code has the smallest number of parameters is the one that will be perceived (Figure 5).

The idea that the brevity of such a code could predict perceptual outcomes, led to an influential development in the goodness camp: Chater's (1996) application of minimum description length (MDL; Rissanen, 1978, 1983) to perceptual organization. In a widely-cited article, Chater makes a strong claim:

${ }^{8}$ Marr (1982) would later bemoan this shortcoming:

... the Gestalt school of psychology ... was concerned with describing the qualities of wholes ... and with trying to formulate "laws" that governed the creation of these wholes. The attempt failed for various reasons, and the Gestalt school dissolved into the fog of subjectivism. With the death of the school, many of the early and genuine insights were unfortunately lost to the mainstream of experimental psychology. (pp. 8-9)

Sadly, he died in 1980 unaware that a revival was on its way (Beck, 1982; Kanizsa, 1979; Kubovy \& Pomerantz, 1981), which continues unabated (Wagemans, Elder, et al., 2012; Wagemans, Feldman, et al., 2012).

${ }^{9}$ Such as Garner's (1970) idea that "Good patterns have few alternatives," which (for a limited class of simple dot patterns) means that an index of goodness is the inverse of the cardinality of the orbit of a group consisting of the operations of rotation and reflection applied to the pattern. 


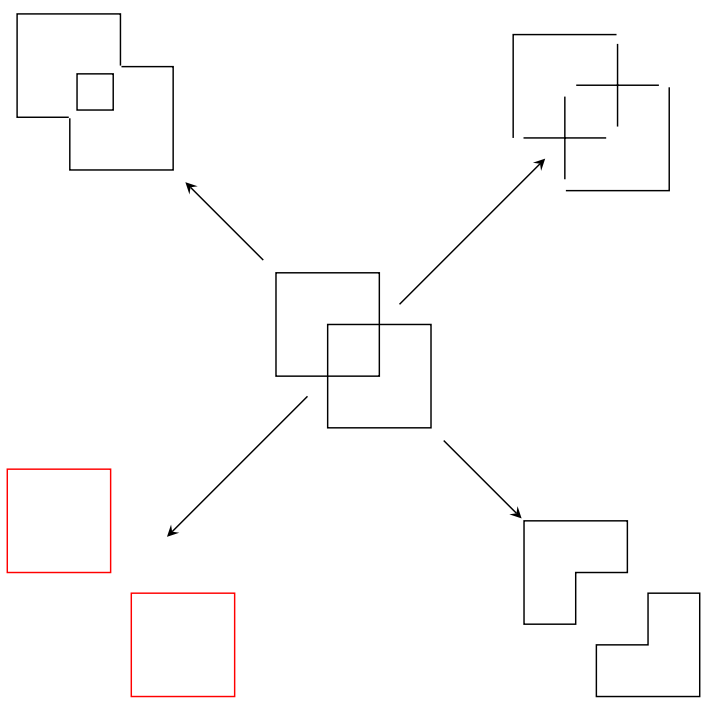

Figure 4. The pattern in the center can be interpreted by SIT in at least four ways. Each corresponds to a different code (a recipe for the reconstruction of the pattern) with a different number of structural information parameters. The pattern in red has the shortest code. (Redrawn from Leeuwenberg, 1978, Figure 1).

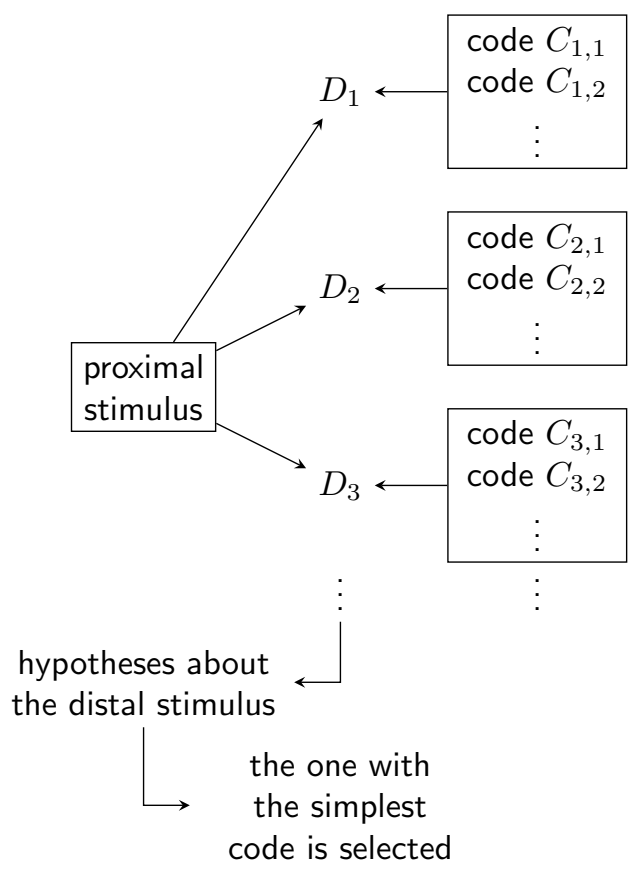

Figure 5. van der Helm's (2014) account of the simplicity principle according to Structural Information Theory (SIT). (Redrawn from van der Helm, 2014, Figure 1.11.)

the simplicity and likelihood principles in perceptual organization are equivalent, given natural interpretations of simplicity in terms of shortest description length 
and of likelihood in terms of probability theory. This implies that the empirical and theoretical debate over whether perceptual organization maximizes simplicity or maximizes likelihood is misguided. (p. 579)

MDL is a method to find structure in data. ${ }^{10}$ Imagine three sequences of $n=10,000$ binary numbers described in the first column of Table 1. The first sequence obeys a Table 1

Compression of three binary sequences of length $n=10,000$.

\begin{tabular}{llll}
\hline \multicolumn{1}{c}{ sequence } & apparent structure & \multicolumn{1}{c}{ program } & size \\
\hline $\begin{array}{l}0001 \\
\text { repeated 2500 times }\end{array}$ & $\begin{array}{l}\text { obeys a } \\
\text { deterministic 'law' }\end{array}$ & $\begin{array}{l}\text { for i }=1 \text { to 2500; } \\
\text { print '0001'; next; halt }\end{array}$ & $O(\log n)$ \\
\hline $\begin{array}{l}\text { 011 . . 101: } \\
n \text { tosses of a fair coin }\end{array}$ & none & print '011...'; halt & $n$ \\
\hline$n$ tosses of a biased & obeys a & & $\alpha * 10,000$, \\
coin, where $p(0)=0.8$ & probabilistic 'law' & & where $0<\alpha<1$ \\
\hline
\end{tabular}

deterministic 'law' ("repeat '0001' 2500 times"); it is thus perfectly predictable. If we wrote a Pascal-like program to generate it, we would get:

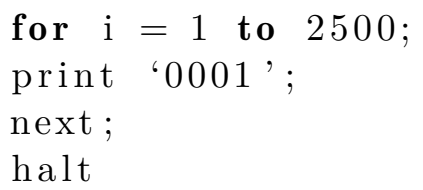

This program is much shorter than the 10,000 characters in the original sequence. In general, a deterministic sequence can be compressed to a length $O(\log n)$. The second sequence in Table 1 is random. Such sequences cannot be compressed at all. The shortest program can do no better than printing out the entire 10,000-character sequence:

print '011..101';

halt

In between the two is the third sequence in Table 1, which follows a probabilistic 'law.' Such sequences can be compressed to a length $\alpha * 10,000$, where $0<\alpha<1$.

Chater's position (anticipated by Perkins, 1976) has been controversial: it was endorsed by Feldman (2009, 2016b); Friston (2008); Thornton (2014), but rejected by van der Helm (2000, 2011, 2016). In the second part of this article (on page 18) we will see that Chater's striking assertion is not consistent with the purpose for which MDL was developed, and is therefore misleading.

\section{Simplicity vs. likelihood was the wrong question}

So what is the upshot of this survey? That we should not treat the relation between the inferential camp and the goodness camp as a contest. To see why, we revisit Pomerantz and

\footnotetext{
${ }^{10}$ The remainder of this paragraph is a paraphrase of P. Grünwald (2005, §1.2).
} 
Kubovy (1988), who weigh the relative merits of likelihood and simplicity. Their review is in two parts. They first contrast the principles as accounts of six Gestalt laws of organization (area, proximity, closure, good continuation, convexity, and symmetry). They find that the likelihood principle better accounts for four (area, proximity, closure, convexity), the simplicity principle better accounts for one (symmetry), and they are tied for one (good continuation). After examining additional perceptual phenomena, such as depth cues, the Necker cube, impossible figures, apparent motion, and conclude that

Our assessment leans toward the likelihood principle as the best overall description of how perceptual organization operates. However, an acceptance of likelihood does not mandate a rejection of prägnanz, because the two are not mutually exclusive. As we have seen, certain phenomena support prägnanz, so a compromise could be sought that captures the essentials of both positions without diluting the positive contributions of either or endangering the parsimony of any definitive framework for perceptual organization. (p. 36-32)

To illustrate their point, consider the two shapes in Panel 6a. If we slide them

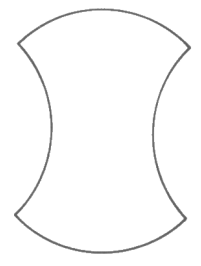

(a) Two shapes side-by-side.

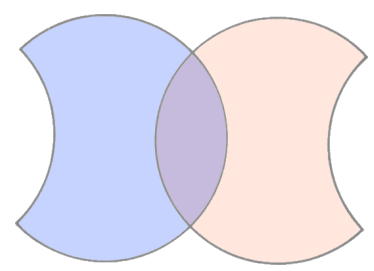

(c) they seem to overlap;

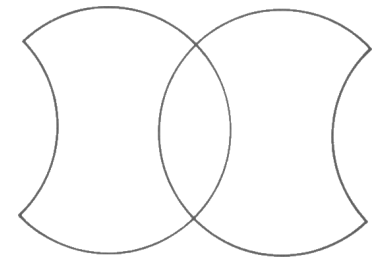

(b) If we make them touch ...

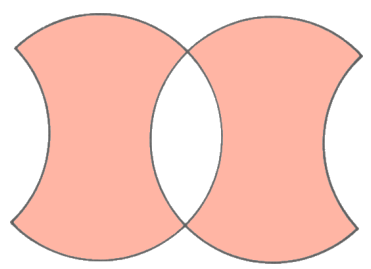

(d) they do not seem to abut.

Figure 6. An example of the simplicity and the likelihood principles making the same prediction. (After Kanizsa, 1979, Figure 5.8.)

horizontally toward each other until they abut, we get Panel 6b. Panel 6b is perceived as Panel 6c and not (as might be expected from Panel 6a), as Panel 6d. The phenomenon is readily accounted for by the simplicity principle: In Panel $6 \mathrm{c}$ smooth contours trump the symmetry of the forms in Panel 6d.

But the percept is just as easily explained by the likelihood principle. In Panel 6a the relative position of the two shapes is nonaccidental; whereas, in Panel 6d their relative position is accidental, i.e., unlikely. In contrast, the relative position of the two shapes in Panel $6 \mathrm{c}$ is accidental, i.e., more likely.

This rejection of the simplicity-likelihood debate is not without precedent. The history of psychology is strewn with the debris of illusory competitions (Greenwald, 2004, 2012). So 
we take Pomerantz and Kubovy's conclusions (quoted earlier) a step further, and exhort our colleagues to eschew debates between the Helmholtzian and the Gestalt camps.

Rather, we propose to recast the question as a problem that any perceptual system must confront: what is the optimal level of simplicity of a perceptual model of the world?

\section{Part 2: The way forward - The question of optimal complexity}

We concluded the first part of this article with a cris de cour: we should not waste our resources on the unresolvable question that sets likelihood and simplicity in opposition. We rejected the opposition:

$$
\text { likelihood } \longleftrightarrow \text { simplicity, }
$$

To break the impasse, let us assume that perceptual systems are species- and situationspecific devices, evolved to construct models of the world that are useful for the propagation of that species. The key term here is model.

\section{Evolution and perceptual models}

To start, we note a weakness in the position of the Inferential Camp. The followers of Helmholtz (as well as many others, as Hoffman, 2006, shows) believe in the mimetic function of perception:

... a goal of perception is to match, or at least to approximate, true properties of a physical world that is assumed to exist independent of any acts of observation. (p. 201)

Now if the function of perceptual systems were to represent the physical world as well as possible, such systems would maximize the accuracy of their models without regard for their complexity. But as we saw in the preceding section, this is not the true; those who have pursued the simplicity principle have marshaled considerable evidence.

It is more plausible to assume that the function of perceptual systems is to provide animals with adaptive information (both species- and situation-specific) about the ecological niche (Grinnell, 1917) in which they live (which von Uexküll 1928; von Uexküll Jakob 1973, called the animal's Umwelt); assumptions that led to the development of Perceptual Interface Theory (Hoffman, 2006, 2008, 2009; Hoffman, Singh, \& Prakash, 2015; Mark, Marion, \& Hoffman, 2010). This information need not be a faithful representation of the environment,

only an effective one. A valuable source of evidence in support of the argument of Hoffman and his colleagues is the existence of supernormal responses to stimuli Table 2.

There are parallel phenomena in human visual perception. For one, there is the perception of cuteness (Figure 7). Kringelbach, Stark, Alexander, Bornstein, and Stein (2016) have shown that:

cuteness supports key parental capacities by igniting fast privileged neural activity followed by slower processing in large brain networks also involved in play, empathy, and perhaps even higher-order moral emotions. (p. 545) 
Table 2

Examples of supernormality (based on Ross-Smith, 2009, \$4.1.1)

animal

subgroup

domain

stimulus

\begin{tabular}{cll}
\hline birds & $\begin{array}{l}\text { breeding } \\
\text { mate choice } \\
\text { feeding in brood parasites }\end{array}$ & $\begin{array}{l}\text { egg size, \& color } \\
\text { tail length; crest (in crestless species) } \\
\text { large, colorful gapes and intense begging calls }\end{array}$ \\
\hline fishes & agonistic behavior & preference for red \\
\hline \multirow{2}{*}{ amphibians } & frog mating call & $\begin{array}{l}\text { suffix to mating call (where none occur in that } \\
\text { species) }\end{array}$ \\
\hline insects & $\begin{array}{l}\text { mating in butterflies } \\
\text { mating in moths }\end{array}$ & $\begin{array}{l}\text { enhanced frequency of the female wing-flash } \\
\text { supernormally attractive artificial pheromones } \\
\text { nuptial gifts, even if this form of mating behaviour } \\
\text { has not evolved in that species }\end{array}$ \\
\hline
\end{tabular}
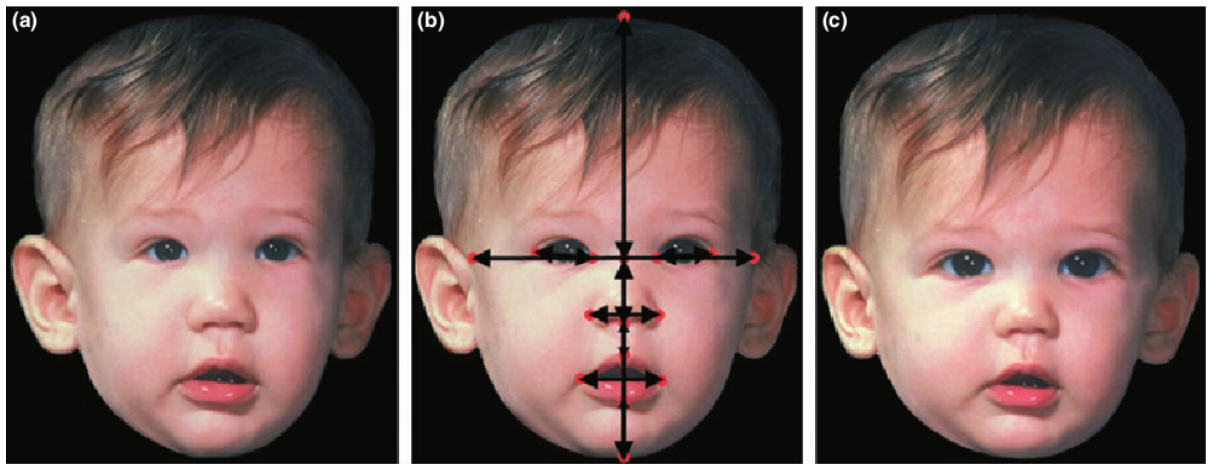

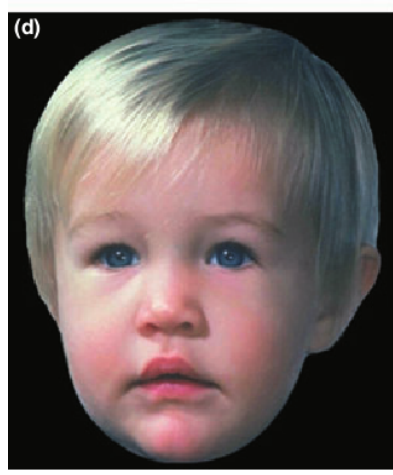

low baby schema

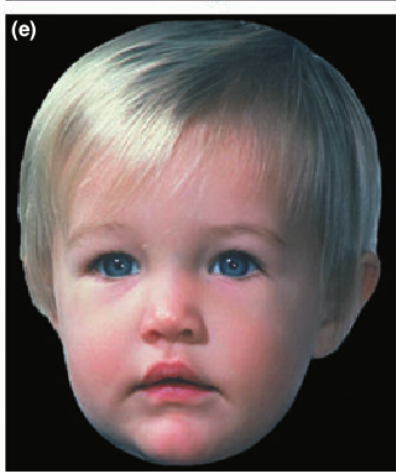

unmanipulated

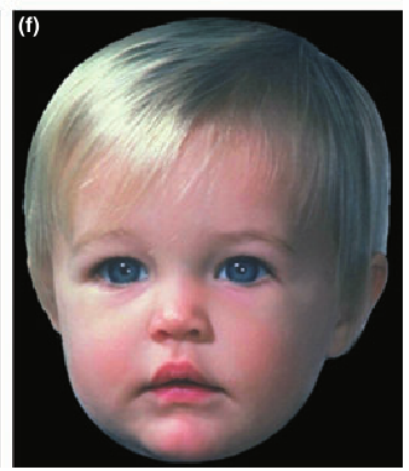

high baby schema

Figure 7. Baby schema with (in upper middle picture) facial landmarks represented by red dots and measures represented by arrows (Glocker et al., 2009, Figure 1). 


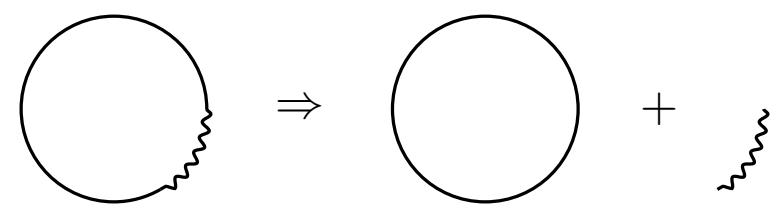

Figure 8. Schema with correction: the pattern on the left is likely to be interpreted as circle with a squiggle, shown on the right.

As a further example, consider a pattern such as the one on the left in Figure 8. If the visual system were aiming for a faithful representation of objects, it would be perceived or described in such a way as to allow its reconstruction, roughly thus:

a circular arc with center $(x, y)$ and radius $r$, from 0 to $300^{\circ}$, and a sinusoidallyperturbed arc (consisting of 5.5 cycles of amplitude $a$ ) from 300 to $360^{\circ}$.

But this is not how our visual system operates. There is good reason to believe that we neither register the number of bumps in the squiggle, nor the positions of its endpoints on the circumference. Indeed it is most plausible that our description will decompose it into a circle modified by a squiggle (right-hand panel of Figure 8) namely, a schema with correction, ${ }^{11}$ a canonical form and an accidental feature.

This brings us to the question of the appropriate level of complexity of an animal's perceptual interface (its Umwelt). If it is too simple, crucial information may be lacking, if too complex, it wastes computational resources. Hoffman (2009, p. 148) puts it thus:

Principle of Satisficing Categories: Each perceptual category of an organism, to the extent that the category is shaped by natural selection, is a satisficing solution to adaptive problems.

where a satisficing solution

1. is only a local maximum of fitness (Figure 9),

2. depends on features of the animal, such as:

(a) costs of classification errors,

(b) resources required to compute a category,

(c) structures already present in the animal, which make exaptation (Gould \& Vrba, 1982) possible,

3. depends on features of the niche, such as:

(a) predators and prey,

(b) mates.

\section{The optimal complexity of models}

A case study: the map of the London Underground. In the 1930s, the London Underground was losing money. Some attributed this to a confusing map (similar to

\footnotetext{
${ }^{11}$ Although the expression is often attributed to Bartlett (1932), Woodworth (1938) attributes the idea to Kuhlmann (1906) and even quotes from his article:

... a certain square was seen as "a square with a nick on the side." (p. 74, presumably referring to Fig. 17 on p. 72 )

Unfortunately, I was unable to find the quote (or the figure) in Kuhlmann's article.
} 


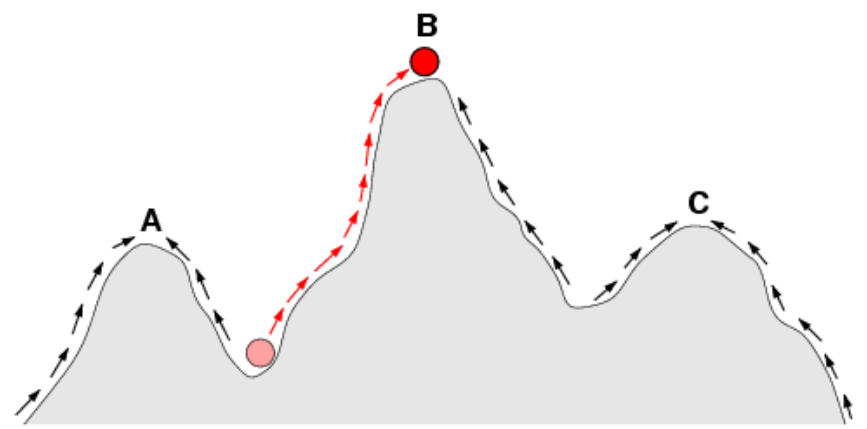

Figure 9. Sketch of a fitness landscape. The arrows indicate the preferred flow of a population on the landscape, and the points $\mathrm{A}$ and $\mathrm{C}$ are local optima. The red ball indicates a population that has moved from a very low fitness value to the top of a peak. (Image in the public domain, https://commons.wikimedia.org/w/index.php?curid=193687.)

Panel 10b), which was a smoothed approximation to geographic reality. In 1933, in an effort

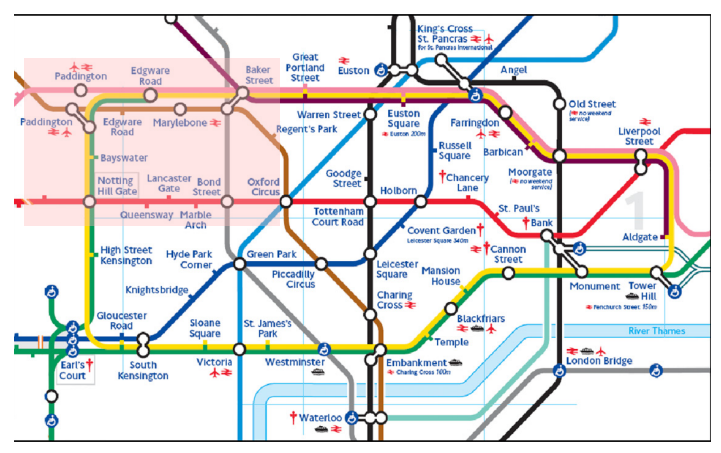

(a) Standard schematic map (Guo, 2011, Figure $2 \mathrm{~b})$.

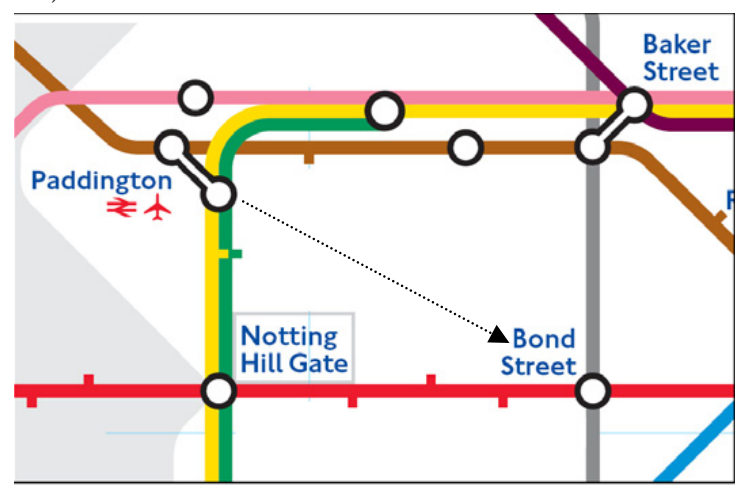

(c) Zoomed pink rectangle in panel (a) (Guo, 2011, Figure 4a).

Figure 10. Maps of London Underground.

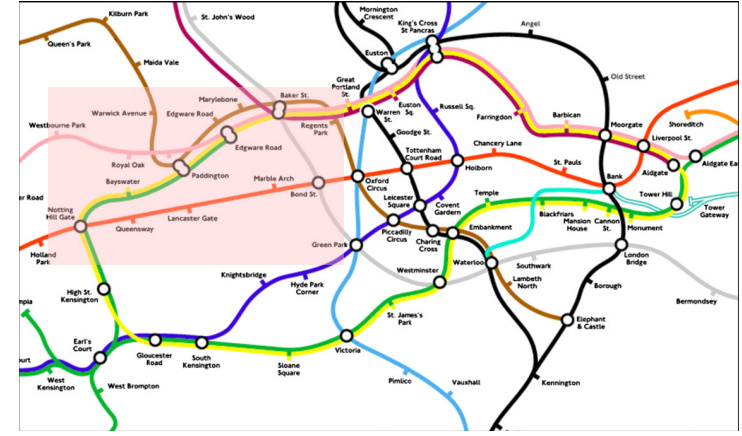

(b) Smoothed geographically correct map (Guo, 2011, Figure 2a).

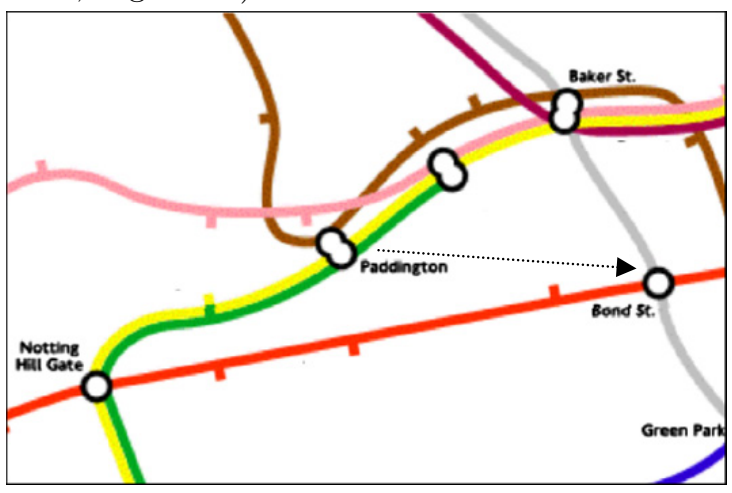

(d) Zoomed pink rectangle in panel (b) (Guo, 2011, Figure 4b).

to mitigate the problem, the newly-formed London Passenger Transport Board replaced it with the familiar map of the Underground (Panel 10a), in which lines were octolinear (vertical, horizontal, or diagonal - Degani, 2013). 
As a consequence, the correlation between map distance and actual distance dropped $(r=0.22$; Guo, 2011), which resulted in less efficient travel. If you wish to go from Paddington Station to Bond Street (represented in Panels 10c and 10d by a dotted arrow), you have two choices. You can take Route $B$, which requires you to transfer at Baker Street, or Route $N$, which requires you to transfer at Notting Hill Gate. Even though - disregarding transfer time - Route $N$ is $15 \%$ slower than Route B, over 30\% of passengers take it (Guo, 2011). This makes sense for users of the standard schematic map (Panel 10c): Paddington and Bond Street appear to be on opposite corners of a rectangle, and the representation of route $N$ is $10 \%$ shorter. Had a geographically more faithful representation been used (Panel 10d), evidence indicates that fewer passengers would take the longer route.

This tradeoff between legibility and efficiency implies that there may be a level of complexity at which the two benefits are properly balanced.

The bias-variance tradeoff. Maps are graphic models. The tradeoff that characterizes maps of the London Underground has been studied in the theory of statistical models, where it is called the bias-variance tradeoff. Suppose we have the data points shown in gray in the three panels at the bottom of Figure $11,{ }^{12}$ and we are privy to the data generator - a third-degree polynomial, $f$, contaminated by normally-distributed noise. ${ }^{13}$ Our task is to find a model of the data. If we use a linear fit $(\mathrm{df}=1)$, represented by the line in left-hand panel at the bottom of Figure 11, the fit to $f$ and the data is poor. If we fit a more complex cubic spline (Hansford \& Farin, 2002), with $\mathrm{df}=5$, as in the central panel, it looks like we have come close to $f$, but the model does not captuare the ups and downs of the data points. Finally, if we fit an even more complex cubic spline $(\mathrm{df}=25)$, represented by the jagged line in the right-hand panel, we track the individual data points well, but our curve doesn't resemble $f$. In other words, as we increase the complexity of our model, we better capture the particularities of our current data. In technical terms, by increasing the number of degrees of freedom, we have reduced the bias of the model, or equivalently, we have increased the goodness of fit of the model. This is what the peach-colored line in the main panel of Figure 11 shows.

But this improvement in goodness of fit comes at a price. Let us repeatedly (say 10,000 times) draw samples from the same population, and each time we fit twenty-five models with degrees of freedom $\mathrm{df}=1,2, \ldots, 25$. As this complexity increases, the sample-to-sample variability of the parameters of the 10,000 models increases. In technical terms, by increasing model complexity, we have increased the variance of the model. As a result, beyond a certain level of model complexity our ability to generalize our model decreases: the function has a maximum. This relationship between the complexity of a model and its generalizability is represented by the concave lime-colored line.

The peak of the generalizability function represents the optimal complexity of the model. It answers the question, How many degrees of freedom should we invest in the model in order to maximize its generalizability?

This is a akin to a decision by by Consumer Reports to give a Best Buy accolade to item $B$, whose quality may be slightly lower than item $A$, but whose cost is considerably lower. Degrees of freedom may be thought of as a limited resource available to invest in a

\footnotetext{
${ }^{12}$ Computations based on R-code by Venturini (here, amended in an email message of 24 Sept, 2016), inspired by James, Witten, Hastie, and Tibshirani $(2014, \S 2.2)$.

${ }^{13} y=f(x)=5-10^{-1} x+4 \times 10^{-3} x^{2}-3 \times 10^{-5} x^{3}+\varepsilon$ where $\varepsilon \sim N\left(\mu=0, \sigma_{\varepsilon}^{2}=0.25\right)$.
} 


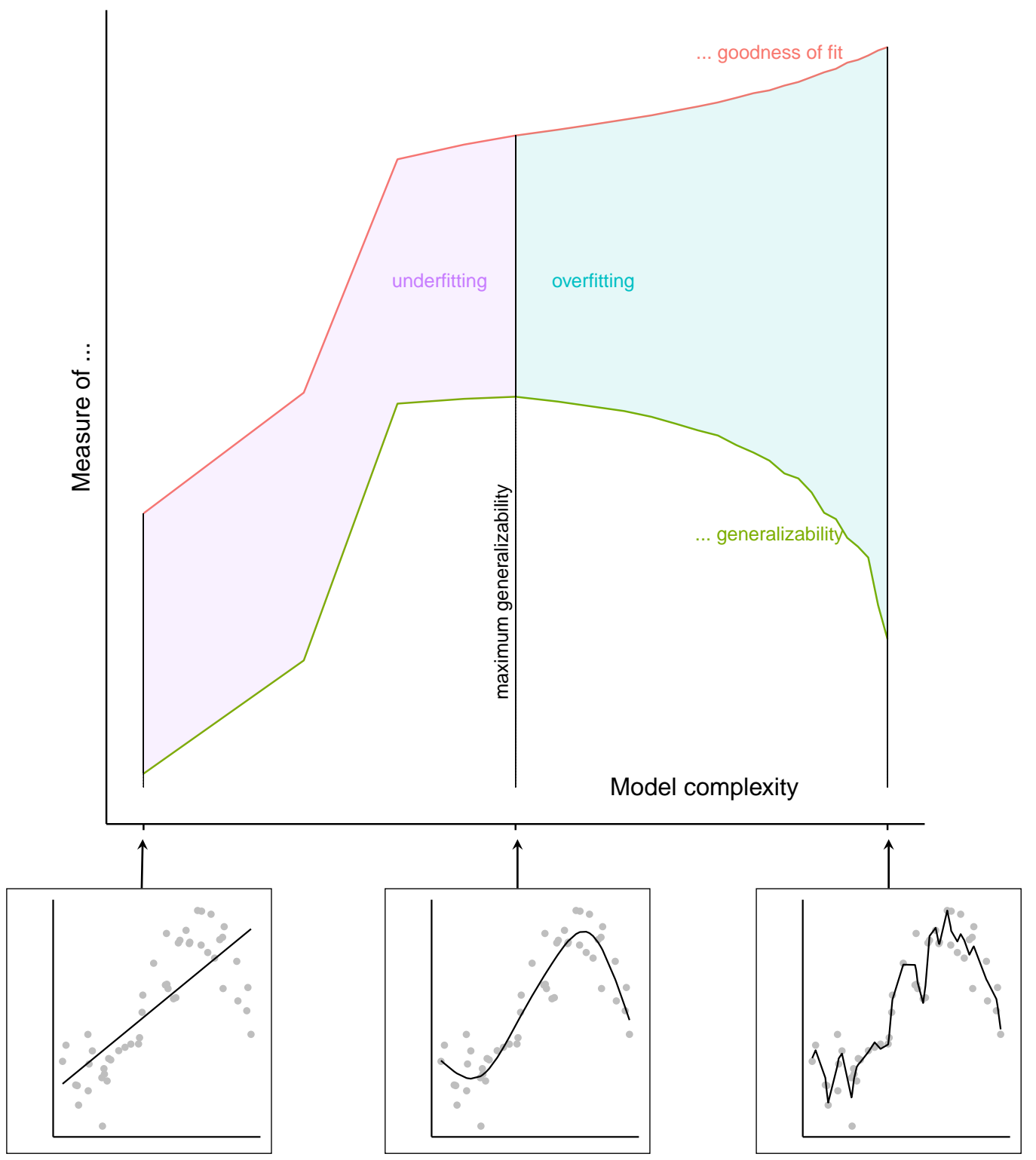

Figure 11. The bias-variance tradeoff as a function of model complexity, indexed by degrees of freedom (df) in the model. Three framed panels show the data (gray points) estimated using 1,5 , and $25 \mathrm{df}$. In the main panel, the "goodness of fit" line rises with df $(=1, \ldots, 25)$; "generalizability" rises with df and then falls.

model. Assume that we have selected a model with the degrees of freedom that corresponds to the greatest generalizability. This is the model with the lowest df per unit of goodness of fit, a best buy. 


\section{Perceptual mechanisms and the best buy}

The heuristic understanding that evolution may have produced best-buy solutions to the problem of model complexity is not enough. However plausible, it remains a Kiplingstyle just-so story (How the Herring Gull got his red dot). It would be useful to obtain experimental evidence of best-buy solutions in action. Earlier (page 12) I suggested that rather than asking whether perceptual systems maximize likelihood or simplicity, we ask whether they optimize the complexity of their model(s) of the world. But something is missing: in presenting the bias-variance tradeoff we made the assumption that $f$ is known. This, of course, is not the case for perceptual systems, which need a criterion to select the model of the world with the greatest generalizability.

In statistical estimation theory this problem remained unsolved until some four decades ago when Akaike (1974), in a landmark article, introduced AIC (which stood for an information criterion, but now stands for the Akaike information criterion). It is shown in the first row of Table 3. In the formula for AIC, $\theta$ is the vector of model parameters,

Table 3

Two criteria for finding the sweet spot of model complexity that minimizes bias $^{2}+$ variance. All such criteria, including $M D L$, are the sum of an estimate of prediction error and a penalty for model complexity.

\begin{tabular}{rlll}
\hline criterion & prediction error & & penalty \\
\hline AIC & $=-2 \ln \mathcal{L}_{\max }(\hat{\theta})$ & + & $2 k$ \\
BIC & $=-2 \ln \mathcal{L}_{\max }(\hat{\theta})$ & + & $2 k \ln N$ \\
\hline
\end{tabular}

$\ln \mathcal{L}_{\max }(\hat{\theta})$ is the likelihood of the candidate model given the data when evaluated at $\hat{\theta}$, the maximum likelihood estimate of $\theta$, and $k$ is the number of estimated parameters in the candidate model. The candidate model with the lowest AIC is expected to have the lowest test MSE. Furthermore, Stone (1977) shows that asymptotically, model selection by cross-validation is equivalent to model-selection by AIC.

As Table 3 shows, AIC has two parts. The term in the prediction error column is conceptually equivalent (in a maximum-likelihood estimation framework) to what we earlier referred to as the model's bias. The term in the penalty column penalizes the model for its complexity. AIC adds the penalty $2 k$, where $k$ is the number of estimated parameters.

Since 1974, several statisticians have proposed alternative information criteria, each based on different premises, but all having the same two-part structure. For example, in the BIC, the Bayesian Information Criterion (Schwarz, 1978) (second row of Table 3), the estimate of prediction error is the same as for AIC, but the penalty for complexity is heavier. It is $2 k \ln N$, where $k=$ the number of estimated parameters and $N=$ the number of data points.

A further example is Minimum Description Length (MDL) introduced by Rissanen (1978). Earlier (page 9) we noted Chater's (1996) assertion, "the simplicity and likelihood principles in perceptual organization are equivalent." Unfortunately this statement is based on a misunderstanding of the purpose for which the minimum description length (MDL) 
was developed. Rissanen (1978) did not develop MDL as a way to quantify simplicity, but as a criterion for model selection that is improves upon AIC and BIC. Indeed both are close relatives of MDL: AIC is an "expectation-based MDL," and under some conditions, "MDL is asymptotically BIC" (both quotes from P. D. Grünwald, 2007, p. 552).

With this grasp of the model-selection problem, one can ask whether perceptual systems have evolved an model-selection criterion analogous to AIC, BIC, or MDL. Unfortunately the topic is in its infancy. I can offer only once example: the pioneering work of Briscoe and Feldman (2011) on concept-learning, which provides us with an example of how such research might proceed. In their paper they do not accept the competition between exemplar-based and prototype-based models of concept learning. In reverse, they treat these as endpoints of a scale of model complexity. At one end of the scale are prototype models, whose conceptual form is simple, and at the other are exemplar models, which can entertain complex hypotheses. Prototype models are inflexible, and may not fit the data well, and as a consequence they manifest high bias. Exemplar models are so flexible that they can faithfully capture any set of data, and as a consequence the manifest high variance. In a study of human learners they determined each participant's position on this scale by "confronting them with category structures at variable levels of intrinsic complexity." They found that the complexity of the concepts formed by the learners is intermediate between the simplicity of a prototype theory and the complexity of an exemplar model.

I believe that this question is meaningful. Whether it is empirically tractable is an open question.

Where there previously was opposition, we have a triad:

$$
\text { likelihood } \stackrel{\text { simplicity }}{\longleftrightarrow} \text { generalizability. }
$$


References

Aborn, M., \& Rubenstein, H. (1952). Information theory and immediate recall. Journal of Experimental Psychology, 44(4), 260-266. doi: doi:10.1037/h0061660

Aggelopoulos, N. C. (2015). Perceptual inference. Neuroscience $\& 3$ Biobehavioral Reviews, 55, 375-392. doi: doi:10.1016/j.neubiorev.2015.05.001

Akaike, H. (1974). A new look at the statistical model identification. IEEE Transactions on Automatic Control, AC-19(6), 716-723. doi: doi:10.1109/TAC.1974.1100705

Ames, A. (1951). Visual perception and the rotating trapezoidal window. Psychological Monographs: General and Applied, 65(7), i-32. doi: doi:10.1037/h0093600

Attneave, F. (1954). Some informational aspects of visual perception. Psychological Review, 61(3), 183-193. doi: doi:0.1037/h0054663

Attneave, F. (1955). Symmetry, information, and memory for patterns. The American Journal of Psychology, 68(2), 209-222. doi: doi:10.2307/1418892

Bartlett, F. C. (1932). Remembering: A study in experimental and social psychology. London, UK: Cambridge University Press.

Beck, J. (Ed.). (1982). Organization and representation in perception. Hillsdale, NJ, US: Lawrence Erlbaum.

Bowers, J. S., \& Davis, C. J. (2012). Bayesian just-so stories in psychology and neuroscience. Psychological Bulletin, 138(3), 389-414.

Briscoe, E., \& Feldman, J. (2011). Conceptual complexity and the bias/variance tradeoff. Cognition, 118(1), 2-16. doi: doi:10.1016/j.cognition.2010.10.004

Brunswik, E. (1940). Thing constancy as measured by correlation coefficients. Psychological Review, 47(1), 69-78. doi: doi:10.1037/h0057921

Brunswik, E. (1944). Distal focussing of perception: Size-constancy in a representative sample of situations. Psychological Monographs, 56(1), i-49. doi: doi:10.1037/h0093505

Brunswik, E. (1955). Representative design and probabilistic theory in a functional psychology. Psychological Review, 62 (3), 193-217. doi: doi:10.1037/h0047470

Brunswik, E., \& Kamiya, J. (1953). Ecological cue-validity of "proximity" and other Gestalt factors. The American Journal of Psychology, 66(1), 20-32. doi: doi:10.2307/1417965

Cabrera, F. (2017). Can there be a Bayesian explanationism? On the prospects of a productive partnership. Synthese, 194(4), 1245-1272. doi: doi:10.1007/s11229-015-0990-z

Chater, N. (1996). Reconciling simplicity and likelihood principles in perceptual organization. Psychological Review, 103(3), 566-581. doi: doi:10.1037/0033-295X.103.3.566

Degani, A. (2013). A tale of two maps: Analysis of the london underground "diagram". Ergonomics in Design: The Quarterly of Human Factors Applications, 21(3), 7-16. doi: doi:10.1177/1064804613489125

Elder, J. H., Victor, J. D., \& Zucker, S. W. (2016). Understanding the statistics of the natural environment and their implications for vision. Vision Research, 120, 1-4. (Editorial for special issue on Vision and the Statistics of the Natural Environment) doi: doi:10.1016/j.visres.2016.01.003

Feldman, J. (2009). Bayes and the simplicity principle in perception. Psychological Review, 116(4), 875-887. doi: doi:10.1037/a0017144

Feldman, J. (2013). Tuning your priors to the world. Topics in Cognitive Science, 5(1), 13-34. doi: doi:10.1111/tops.12003

Feldman, J. (2016a). Bayesian models of perceptual organization. In J. Wagemans (Ed.), Oxford handbook of perceptual organization. Oxford University Press.

Feldman, J. (2016b). The simplicity principle in perception and cognition. Wiley Interdisciplinary Reviews: Cognitive Science. doi: doi:10.1002/wcs.1406

Feldman, J., \& Singh, M. (2005). Information along contours and object boundaries. Psychological Review, 112(1), 243-252. doi: doi:10.1037/0033-295X.112.1.243

Fitts, P. M. (1954). The information capacity of the human motor system in controlling the amplitude 
of movement. Journal of Experimental Psychology, 47(6), 381-391. doi: doi:10.1037/h0055392

Friston, K. (2008). Hierarchical models in the brain. PLoS Computational Biolology, 4(11), e1000211. doi: doi:10.1371/journal.pcbi.1000211

Garner, W. R. (1970). Good patterns have few alternatives: Information theory's concept of redundancy helps in understanding the Gestalt concept of goodness. American Scientist, 58(1), $34-42$.

Geisler, W. S. (2007). Visual perception and the statistical properties of natural scenes. Annual Review of Psychology, 59(1), 167-192. doi: doi:10.1146/annurev.psych.58.110405.085632

Glocker, M. L., Langleben, D. D., Ruparel, K., Loughead, J. W., Gur, R. C., \& Sachser, N. (2009). Baby schema in infant faces induces cuteness perception and motivation for caretaking in adults. Ethology, 115 (3), 257-263. doi: doi:10.1111/j.1439-0310.2008.01603.x

Gould, S. J., \& Vrba, E. S. (1982). Exaptation - a missing term in the science of form. Paleobiology, 8(1), 4-15. doi: doi:10.1017/S0094837300004310

Greenwald, A. G. (2004). The resting parrot, the dessert stomach, and other perfectly defensible theories. In J. T. Jost, M. R. Banaji, \& D. A. Prentice (Eds.), Perspectivism in social psychology: The yin and yang of scientific progress (pp. 275-285). Washington, DC, US: American Psychological Association. doi: doi:10.1037/10750-020

Greenwald, A. G. (2012). There is nothing so theoretical as a good method. Perspectives on Psychological Science, 7(2), 99-108. doi: doi:10.1177/1745691611434210

Gregory, R. L. (1970). The intelligent eye. New York, NY, US: McGraw-Hill.

Grinnell, J. (1917). The niche-relationships of the California Thrasher. The Auk, 34(427-433).

Grossman, E. R. F. W. (1953). Entropy and choice time: The effect of frequency unbalance on choice-response. Quarterly Journal of Experimental Psychology, 5(2), 41-51. doi: doi:10.1080/17470215308416625

Grünwald, P. (2005). A tutorial introduction to the minimum description length principle. In P. D. Grünwald, I. J. Myung, \& M. A. Pitt (Eds.), Advances in minimum description length: Theory and applications (pp. 3-80). Cambridge, MA, US: MIT Press. (First published as arXiv:math/0406077 [math.ST])

Grünwald, P. D. (2007). The minimum description length principle. Cambridge, MA, US: The MIT Press.

Guo, Z. (2011). Mind the map! The impact of transit maps on path choice in public transit. Transportation Research Part A: Policy and Practice, 45 (7), 625-639. doi: doi:10.1016/j.tra.2011.04.001

Hansford, D., \& Farin, G. (2002). Curve and surface constructions. In G. Farin, J. Hoschek, \& M.-S. Kim (Eds.), Handbook of computer aided geometric design (pp. 165-192). Amsterdam, NL: Elsevier.

Harman, G. H. (1965). The inference to the best explanation. The Philosophical Review, 74 (1), 88-95. doi: doi: $10.2307 / 2183532$

Hatfield, G., \& Epstein, W. (1985). The status of the minimum principle in the theoretical analysis of visual perception. Psychological Bulletin, 97(2), 155-186. doi: doi:10.1037/0033-2909.97.2.155

Helmholtz, H. L. F. v. (2000). Helmholtz's Treatise on Physiological Optics (Vol. 3; J. P. C. Southall, Ed.). Bristol, UK: Thoemmes Press. (Translation first published in 1925 of volume three of the third [1910] edition of Handbuch der physiologischen Optik.)

Henderson, L. (2014). Bayesianism and inference to the best explanation. British Journal for the Philosophy of Science, 65(4), 687-715. doi: doi:10.1093/bjps/axt020

Hick, W. E. (1952). On the rate of gain of information. Quarterly Journal of Experimental Psychology, 4 (1), 11-26. doi: doi:10.1080/17470215208416600

Hoffman, D. D. (1998). Visual intelligence: How we create what we see. Now York, NY, US: W. W. Norton.

Hoffman, D. D. (2006). Mimesis and its perceptual reflections. In W. Pape (Ed.), A view in the rear-mirror: Romantic aesthetics, culture, and science seen from today. Festschrift for Frederick Burwick on the occasion of his seventieth birthday (pp. 201-209). Trier, DE: WVT, 
Wissenschaftlicher Verlag Trier.

Hoffman, D. D. (2008). Conscious realism and the mind-body problem. Mind and Matter, 6(1), 87-121. (http://www.ingentaconnect.com/content/imp/mm/2008/00000006/ $00000001 /$ art00004)

Hoffman, D. D. (2009). The Interface theory of perception: Natural selection drives true perception to swift extinction. In S. J. Dickinson, A. Leonardis, B. Schiele, \& M. J. Tarr (Eds.), Object categorization: Computer and human vision perspectives (pp. 148-166). Cambridge University Press.

Hoffman, D. D., Singh, M., \& Prakash, C. (2015). The interface theory of perception. Psychonomic Bulletin \& Review, 22 (6), 1480-1506. doi: doi:10.3758/s13423-015-0890-8

James, G., Witten, D., Hastie, T., \& Tibshirani, R. (2014). An introduction to statistical learning with applications in $R$ (2014, corrected ed.). New York, NY, US: Springer.

Jaynes, E. T. (1988). How does the brain do plausible reasoning? In G. J. Erickson \& C. R. Smith (Eds.), Maximum-entropy and Bayesian methods in science and engineering: Foundations (Vols. 31-32, pp. 1-24). Dordrecht, NL: Springer Netherlands. doi: doi:10.1007/978-94-009-3049-0_1

Jones, M., \& Love, B. C. (2011). Bayesian fundamentalism or enlightenment? On the explanatory status and theoretical contributions of Bayesian models of cognition. Behavioral and Brain Sciences, 34(4), 169-188. doi: doi:10.1017/S0140525X10003134

Kanade, T. (1983). Geometrical aspects of interpreting images as a three-dimensional scene. Proceedings of the IEEE, 71 (7), 789-802. doi: doi:10.1109/PROC.1983.12679

Kanizsa, G. (1979). Organization in vision: Essays on Gestalt perception. New York, NY, US: Praeger.

Knill, D. C., Kersten, D., \& Yuille, A. (1996). Introduction: A Bayesian formulation of visual perception. In D. C. Knill \& W. Richards (Eds.), Perception as Bayesian inference (pp. 1-21). Cambridge, UK: Cambridge University Press.

Knill, D. C., \& Richards, W. (Eds.). (1996). Perception as Bayesian inference. Cambridge, UK: Cambridge University Press.

Koffka, K. (1915). Beiträge zur Psychologie der Gestalt. III. Zur Grundlegung der Wahrnehmungspsychologie. Eine Auseinandersetzung mit V. Benussi [Contibutions to Gestalt psychology. III. Toward a foundation of the psychology of perception. A debate with V. Benussi]. Zeitschrift für Pyschologie, 73, 11-90. (Translated extract in Ellis, 1938, pp. 371-378.)

Koffka, K. (1922). Perception: an introduction to the Gestalt-Theorie. Psychological Bulletin, 19(10), 531-585. doi: doi:10.1037/h0072422

Koffka, K. (1963). Principles of Gestalt psychology. New York, NY, USA: Harcourt, Brace \& World. (Original work published 1935)

Köhler, W. (1920). Die physischen Gestalten in Ruhe und im stationären Zustand. Eine naturphilosophische Untersuchung [Physical Gestalts at rest and in steady state. A naturalphilosophical investigation]. Braunschweig, DE: Friedr. Vieweg und Sohn. (Translated extract in Ellis, 1938, pp. 17-54.)

Kringelbach, M. L., Stark, E. A., Alexander, C., Bornstein, M. H., \& Stein, A. (2016). On cuteness: Unlocking the parental brain and beyond. Trends in Cognitive Sciences, 20(7), 545-558. doi: doi:10.1016/j.tics.2016.05.003

Kubovy, M. (1986). The psychology of perspective and Renaissance art. New York, NY, US: Cambridge University Press.

Kubovy, M., \& Epstein, W. (2001). Internalization: A metaphor we can live without. Behavioral and Brain Sciences, 24(4), 618-625, 756-757. doi: doi:10.1017/S0140525X01000048

Kubovy, M., Epstein, W., \& Gepshtein, S. (2013). Visual perception: Theoretical and methodological foundations. In A. F. Healy \& R. W. Proctor (Eds.), Experimental psychology (2nd ed., Vol. 4 in I. B. Weiner (Editor-in-Chief) Handbook of psychology, pp. 85-119). New York, NY, USA: Wiley.

Kubovy, M., \& Pomerantz, J. (Eds.). (1981). Perceptual organization. Hillsdale, NJ, USA: Lawrence 
Erlbaum. (Reprinted in 2017 by Routledge)

Kuhlmann, F. (1906). On the analysis of the memory consciousness: A study in the mental imagery and memory of meaningless visual forms. Psychological Review, 13(5), 316-348. doi: doi:10.1037/h0070461

Leeuwenberg, E. L. J. (1967). Structural information of visual patterns: An efficient coding system in perception (Unpublished doctoral dissertation). Katholieke Universiteit Te Nijmegen, Nijmegen, NL.

Leeuwenberg, E. L. J. (1978). Quantification of certain visual pattern properties: Salience, transparency, similarity. In E. L. J. Leeuwenberg \& H. F. J. M. Buffart (Eds.), Formal theories of visual perception (pp. 277-298). New York, NY, US: Wiley.

Leeuwenberg, E. L. J., \& van der Helm, P. A. (2013). Structural information theory: The simplicity of visual form. Cambridge, UK: Cambridge University Press.

Lowe, D. G., \& Binford, T. O. (1985). The recovery of three-dimensional structure from image curves. IEEE Transactions on Pattern Analysis and Machine Intelligence, PAMI-7(3), 320-326. doi: doi:10.1109/TPAMI.1985.4767660

Luchins, A. S., \& Luchins, E. H. (1999). Isomorphism in Gestalt theory: Comparison of Wertheimer's and Köhler's oncepts. Gestalt Theory, 21(3), 208-234. (Reprinted in Gestalt Theory, 37(1), 69-100.)

Mach, E. (1897). Contributions to the analysis of the sensations. Chicago, IL, US: Open Court. (Translated by C. M. Williams from the first German edition (1885).)

Maloney, L. T., \& Mamassian, P. (2009). Bayesian decision theory as a model of human visual perception: Testing Bayesian transfer. Visual Neuroscience, 26(01), 147-155. doi: doi:10.1017/S0952523808080905

Mark, J. T., Marion, B. B., \& Hoffman, D. D. (2010). Natural selection and veridical perceptions. Journal of Theoretical Biology, 266(4), 504-515. doi: doi:10.1016/j.jtbi.2010.07.020

Marr, D. (1982). Vision: A computational investigation into the human representation and processing of visual information. San Francisco, CA, US: W. H. Freeman.

Miller, G. A. (1953). What is information measurement? American Psychologist, 8(1), 3-11. doi: doi:10.1037/h0057808

Perkins, D. N. (1968). Cubic corners. Quarterly Progress Report, MIT Press Research Laboratory of Electronics, (89), 207-214. (Reprinted in Harvard Project Zero Technical Report no. 5, 1971)

Perkins, D. N. (1971). Geometry and the perception of pictures: Three studies (Technical Report No. 5). Harvard Project Zero. (Contains three essays: "Cubic Corners, "Oblique views of pictures", "The perception of line drawings of simple space forms".)

Perkins, D. N. (1972). Visual discrimination between rectangular and nonrectangular parallelopipeds. Perception 83 Psychophysics, 12(5), 396-400. doi: doi:10.3758/BF03205849

Perkins, D. N. (1976). How good a bet is good form? Perception, 5(4), 393-406. doi: doi:10.1068/p050393

Pizlo, Z. (2001). Perception viewed as an inverse problem. Vision Research, 41(24), 3145-3161. doi: doi:10.1016/S0042-6989(01)00173-0

Pomerantz, J. R., \& Kubovy, M. (1981). Perceptual organization: An overview. In M. Kubovy \& J. Pomerantz (Eds.), Perceptual organization (pp. 423-456). Hillsdale, NJ, USA: Lawrence Erlbaum.

Pomerantz, J. R., \& Kubovy, M. (1988). Theoretical approaches to perceptual organization: Simplicity and likelihood principles. In K. R. Boff, L. Kauffman, \& J. P. Thomas (Eds.), Handbook of perception and human performance (Vol. 2, pp. 36-1-36-46). New York, NY, US: John Wiley \& Sons.

Purves, D., Monson, B. B., Sundararajan, J., \& Wojtach, W. T. (2014). How biological vision succeeds in the physical world. Proceedings of the National Academy of Sciences, 111(13), 4750-4755. doi: doi:10.1073/pnas.1311309111

Rissanen, J. (1978). Modeling by shortest data description. Automatica, 14(5), 465-471. doi: 
doi:10.1016/0005-1098(78)90005-5

Rissanen, J. (1983). A universal prior for integers and estimation by minimum description length. The Annals of Statistics, 11(2), 416-431. doi: doi:10.1214/aos/1176346150

Rock, I. (1983). The logic of perception. Cambridge, MA, US: The MIT Press Press.

Rock, I., \& Gilchrist, A. (1975). The conditions for the perception of the covering and uncovering of a line. The American Journal of Psychology, 88(4), 571-582. doi: doi:10.2307/1421894

Ross-Smith, V. H. (2009). Pecking response in Lesser Black-backed Gull chicks Larus Fuscus (Unpublished doctoral dissertation). Cardiff University.

Salmon, W. C. (2001). Explanation and confirmation: A Bayesian critique of inference to the best explanation. In G. Hon \& S. S. Rakover (Eds.), Explanation: Theoretical approaches and applications (pp. 61-91). Dordrecht, NL: Springer Netherlands. doi: doi:10.1007/978-94-0159731-9 3

Schwarz, G. (1978). Estimating the dimension of a model. The Annals of Statistics, 6(2), 461-464. doi: doi:10.1214/aos/1176344136

Shannon, C. E. (1948). A mathematical theory of communication. The Bell System Technical Journal, 27, 379-423, 623-656. doi: doi:10.1002/j.1538-7305.1948.tb01338.x; 10.1002/j.15387305.1948.tb00917.x

Shepard, R. N. (1984). Ecological constraints on internal representation: Resonant kinematics of perceiving, imagining, thinking, and dreaming. Psychological Review, 91(4), 417-447. doi: doi:10.1037/0033-295X.91.4.417

Shepard, R. N. (1994). Perceptual-cognitive universals as reflections of the world. Psychonomic Bulletin \& Review, 1(1), 2-28. doi: doi:10.3758/BF03200759

Shepard, R. N. (2001). Perceptual-cognitive universals as reflections of the world. Behavioral and Brain Sciences, 24(4), 581-601. doi: doi:10.1017/S0140525X01000012

Stone, M. (1977). An asymptotic equivalence of choice of model by cross-validation and Akaike's criterion. Journal of the Royal Statistical Society. Series B (Methodological), 39(1), 44-47. (http://www.jstor.org/stable/2984877)

Tanner, W., \& Norman, R. (1954). The human use of information-II: Signal detection for the case of an unknown signal parameter. Transactions of the IRE Professional Group on Information Theory, 4(4), 222-227. doi: doi:10.1109/TIT.1954.1057462

Tarantola, A. (2006). Popper, Bayes and the inverse problem. Nature Physics, 2(8), 492-494. doi: doi:10.1038/nphys375

Thornton, C. (2014). Infotropism as the underlying principle of perceptual organization. Journal of Mathematical Psychology, 61, 38 - 44. doi: doi:10.1016/j.jmp.2014.08.002

Tolman, E. C., \& Brunswik, E. (1935). The organism and the causal texture of the environment. Psychological Review, 42(1), 43-77. doi: doi:10.1037/h0062156

van der Helm, P. A. (2014). Simplicity in vision: A multidisciplinary account of perceptual organization. Cambridge, UK: Cambridge University Press.

van der Helm, P. A. (2016). Simplicity in perceptual organization. In J. Wagemans (Ed.), Oxford handbook of perceptual organization. Oxford University Press.

van der Helm, P. A. (2000). Simplicity versus likelihood in visual perception: From surprisals to precisals. Psychological Bulletin, 126(5), 770-800. doi: doi:10.1037/0033-2909.126.5.770

van der Helm, P. A. (2011). Bayesian confusions surrounding simplicity and likelihood in perceptual organization. Acta Psychologica, 138(3), 337-346. doi: doi:10.1016/j.actpsy.2011.09.007

van der Helm, P. A. (2016). Structural coding versus free-energy predictive coding. Psychonomic Bulletin \& Review, 23(3), 663-677. doi: doi:10.3758/s13423-015-0938-9

Vincent, B. T. (2015). A tutorial on Bayesian models of perception. Journal of Mathematical Psychology, 66, 103-114. doi: doi:10.1016/j.jmp.2015.02.001

von Uexküll, J. (1928). Theoretical biology. New York, NY, US: Harcourt, Brace. (Translation of the 1920 (first) edition)

von Uexküll Jakob. (1973). Theoretische Biologie (2nd ed.). Frankfurt, DE: Suhrkamp. (Reprint of 
the 1928 original)

Wagemans, J., Elder, J. H., Kubovy, M., Palmer, S. E., Peterson, M. A., Singh, M., \& von der Heydt, R. (2012). A century of Gestalt psychology in visual perception: I. Perceptual grouping and figure-ground organization. Psychological Bulletin, 138(6), 1172-1217. doi: doi:10.1037/a0029333

Wagemans, J., Feldman, J., Gepshtein, S., Kimchi, R., Pomerantz, J. R., van der Helm, P. A., \& van Leeuwen, C. (2012). A century of Gestalt psychology in visual perception: II. Conceptual and theoretical foundations. Psychological bulletin, 138(6), 1218-1252. doi: doi:10.1037/a0029334

Wertheimer, M. (1912). Experimentelle Studien über das Sehen von Bewegung [Experimental studies on seeing motion]. Zeitschrift für Psychologie, 61(1), 161-265.

Woodworth, R. S. (1938). Experimental psychology. New York, NY, US: H. Holt. 